\title{
Hypercapnia exacerbates the disruption of the blood-brain barrier by inducing interleukin-1 $\beta$ overproduction in the blood of hypoxemic adult rats
}

\author{
HONGGUANG DING ${ }^{1 *}$, XINQIANG LIU ${ }^{1 *}$, XUSHENG LI $^{1 *}$, MIAOYUN WEN $^{1}$, YA LI $^{2}$, \\ YONGLI HAN $^{1}$, LINQIANG HUANG ${ }^{1}$, MENGTING LIU ${ }^{2}$ and HONGKE ZENG ${ }^{1 *}$ \\ ${ }^{1}$ Department of Emergency and Critical Care Medicine, Guangdong Provincial People's Hospital, \\ Guangdong Academy of Medical Sciences, Guangzhou, Guangdong 510080; ${ }^{2}$ School of Medicine, \\ South China University of Technology, Guangzhou, Guangdong 510006, P.R. China
}

Received August 24, 2019; Accepted April 27, 2020

DOI: $10.3892 /$ ijmm.2020.4604

\begin{abstract}
Refractory hypoxemia is the main symptom of acute respiratory distress syndrome (ARDS). Low tidal volume ventilation is routinely applied in clinical practice to correct hypoxemia, which aims to prevent ventilator-induced lung injury. However, this ventilation strategy inevitably leads to hypercapnia. Our previous study demonstrated that hypercapnia aggravated cognitive impairment in hypoxemic rats; however, the underlying mechanism remains unclear. The aim of the present study was to investigate whether hypercapnia exacerbates the blood-brain barrier (BBB) disruption through inducing interleukin (IL)- $1 \beta$ overproduction in the blood of hypoxemic rats. The BBB permeability in a rat model of hypercapnia/hypoxemia was evaluated. The levels of IL-1 $\beta$ in the blood of rats and human whole-blood cultures were assessed. The expression of IL-1 receptor 1 (IL-1R1), phosphorylated IL-1R1-associated kinase (p-IRAK-1) and tight junctional proteins in cerebral vascular endothelial cells was examined in vitro and in vivo. In addition, IL-1Ra, an IL-1 receptor antagonist, was used to determine whether hypercapnia affects tight junctional protein expression in hypoxic cerebral vascular endothelial cells through inducing IL-1 $\beta$
\end{abstract}

Correspondence to: Professor Hongke Zeng, Department of Emergency and Critical Care Medicine, Guangdong Provincial People's Hospital, Guangdong Academy of Medical Sciences, 106 Zhongshan Er Road, Guangzhou, Guangdong 510080, P.R. China

E-mail: zenghongke@vip.163.com

*Contributed equally

Abbreviations: ARDS, acute respiratory distress syndrome; $\mathrm{BBB}$, blood-brain barrier; IL-1 $\beta$, interleukin-1 $\beta$; IL-1R1, IL-1 receptor 1; IL-1Ra, IL-1 receptor antagonist; NF- $\kappa \mathrm{B}$, nuclear factor- $\kappa \mathrm{B}$; RBECs, rat brain capillary endothelial cells

Key words: acute respiratory distress syndrome, blood-brain barrier, interleukin-1 $\beta$, hypercapnia, hypoxemia overproduction. It was observed that hypercapnia alone did not disrupt the $\mathrm{BBB}$, but aggravated the damage to the $\mathrm{BBB}$ integrity in hypoxemic rats. Hypercapnia increased IL-1 $\beta$ expression in the blood of hypoxemic rats as well as in hypoxic human whole-blood cultures. IL-1R1 and p-IRAK-1 expression was increased, while that of tight junctional proteins was reduced by hypercapnia in hypoxemic cerebral vascular endothelial cells in vitro and in vivo. Additionally, the expression of tight junctional proteins was markedly increased following treatment with IL-1Ra. These results suggest that hypercapnia-induced IL-1 $\beta$ overproduction in the hypoxemic blood may decrease tight junctional protein expression in cerebrovascular endothelial cells via the IL-1R1/p-IRAK-1 pathway, further disrupting BBB integrity, and eventually resulting in increased BBB permeability.

\section{Introduction}

Acute respiratory distress syndrome (ARDS) is one of the major critical diseases encountered in intensive care units (1). The main symptom of ARDS is refractory hypoxemia. Low tidal volume ventilation is routinely applied in clinical practice to correct hypoxemia, which aims to reduce the risk of ventilator-induced lung injury (2). However, this ventilation strategy inevitably leads to hypercapnia, which is referred to as 'permissive' hypercapnia (3). Permissive hypercapnia may contribute to an improved outcome in terms of pulmonary function $(4,5)$, but its effects on cerebral function, such as cognitive function, have not been extensively investigated. Indeed, our previous study demonstrated that permissive hypercapnia aggravated cognitive impairment in hypoxemic rats (6); however, the underlying mechanism remains unclear.

It has been reported that there is a close association between disruption of the blood-brain barrier (BBB) and cognitive impairment (7-10). BBB disruption, particularly in the region of the hippocampus, may lead to cognitive dysfunction $(11,12)$. A recent study demonstrated that $\mathrm{BBB}$ breakdown played a predictive role in human cognitive disorders, particularly at the early stages (13). Moreover, Wang et al reported that hyperpermeability of the $\mathrm{BBB}$ resulted in cognitive impairment in a 
rat model of splenectomy (14). However, it remains unknown whether hypercapnia exerts any effects on BBB disruption in hypoxemic rats.

Tight junctions between cerebrovascular endothelial cells play a key role in maintaining the integrity of the BBB. Tight junctional proteins, including zonula occludens (ZO)-1, occludin and claudin-5, are involved in the determination of BBB permeability (15-17). Additionally, previous studies suggested that peripheral inflammation is crucial in the process of BBB disruption $(18,19)$. Interleukin (IL)-1 $\beta$, one of the major pro-inflammatory factors, may also be involved in the disruption of the BBB. Wang et al revealed that IL-1 $\beta$ induced BBB breakdown through suppressing sonic hedgehog expression in astrocytes. They also observed that IL-1 $\beta$ promoted the expression of other inflammatory factors, thereby augmenting inflammation and aggravating BBB disruption (20). It remains to be determined whether hypercapnia would further increase BBB permeability through upregulating IL- $1 \beta$ expression in the blood of hypoxemic rats.

The aim of the present study was to determine whether hypercapnia can exacerbate BBB disruption through inducing IL- $1 \beta$ overproduction in the blood of hypoxemic adult rats, and whether this effect is mediated by triggering the expression of IL-1 receptor 1 (IL-1R1) in cerebrovascular endothelial cells, decreasing the expression of tight junctional proteins, and ultimately increasing BBB permeability.

\section{Materials and methods}

Animals and treatment. Male adult Sprague-Dawley rats $(\mathrm{n}=144)$, aged $\sim 3$ months and weighing 220-250 g, were included in present study. All efforts were made to minimize the number of animals used in the experiments. The rats were fed standard chow and water, and were housed under standard experimental conditions (temperature, $20-25^{\circ} \mathrm{C}$; humidity, 50-70\%) under a 12-h light/dark cycle. All rats were fasted with access to water overnight prior to the experiments. The rat model of hypercapnia/hypoxemia was established as described in our previous study (6). To minimize suffering and distress, the rats were anesthetized with $2 \%$ pentobarbital sodium (30 $\mathrm{mg} / \mathrm{kg}$ by intraperitoneal injection) followed by mechanical ventilation. The tidal volume $(9 \mathrm{ml} / \mathrm{kg}$ body weight $)$, respiratory rate (45 breaths/min), and inspiratory:expiratory ratio (1:1) were fixed. The rats were randomly divided into four groups according to different concentrations of $\mathrm{O}_{2}$ and $\mathrm{CO}_{2}$ as follows: Sham group (exposed to air), hypercapnia group (exposed to $5 \% \mathrm{CO}_{2}$ ), hypoxemia group (exposed to $16 \% \mathrm{O}_{2}$ ), and hypercapnia + hypoxemia group ( $\mathrm{HH}$ group; exposed to $16 \% \mathrm{O}_{2}$ mixed with $\left.5 \% \mathrm{CO}_{2}\right)$. These concentrations $\left(16 \% \mathrm{O}_{2}\right.$ and $5 \% \mathrm{CO}_{2}$ ) were used to maintain the $\mathrm{PO}_{2}$ of arterial blood at $\sim 60 \mathrm{mmHg}$ and the $\mathrm{pH}$ at 7.20-7.25. The right femoral artery was cannulated to collect arterial blood samples. The $\mathrm{PO}_{2}$, $\mathrm{PCO}_{2}$ and $\mathrm{pH}$ of the arterial blood samples were immediately measured by a Blood Gas/Electrolyte Analyzer (Model 5700; Werfen Corporation).

The rats that were used for western blotting and immunofluorescence staining were not subjected to invasive manipulation apart from ventilation. All animals were ventilated for $3 \mathrm{~h}$, after which time they were euthanized by intraperitoneal injection of pentobarbital sodium $(150 \mathrm{mg} / \mathrm{kg})$.
Assessment of $B B B$ permeability. At $3 \mathrm{~h}$ after ventilation, $2 \%$ Evans blue (EB) solution ( $4 \mathrm{ml} / \mathrm{kg}$ ) was injected through the caudal vein. After $1 \mathrm{~h}$, the rats were perfused transcardially with normal saline to remove the intravascular dye, and $4 \%$ paraformaldehyde was used to perfuse the brain. The brains were harvested and incubated in formamide $(1 \mathrm{ml} / 100 \mathrm{mg})$ at $60^{\circ} \mathrm{C}$ for $24 \mathrm{~h}$. The supernatant was separated after centrifugation at $12,000 \times \mathrm{g}$ at $4^{\circ} \mathrm{C}$ for $20 \mathrm{~min}$. The optical density (OD) values were measured at $620 \mathrm{~nm}$ using a spectrophotometer (Multiskan FC IVD; Thermo Fisher Scientific, Inc.).

Human whole-blood cultures and ethics statement. Whole blood was donated by 4 healthy male volunteers (mean age \pm standard deviation, $35 \pm 9.4$ years). None of the volunteers had a history of cancer, hematological disorders, infections, autoimmune diseases, transplantation, or use of immunosuppressive drugs. The whole blood was cultured as reported previously (21). Briefly, $2 \mathrm{ml}$ of whole blood were collected from each volunteer. Subsequently, the whole-blood samples were mixed with $18 \mathrm{ml}$ RPMI-1640 medium (Invitrogen; Thermo Fisher Scientific, Inc., cat. no. 8118329), which was supplemented with $10 \%$ human serum (Gemini Bio-Products; cat. no. H91S001) and $1 \%$ penicillin-streptomycin solution (Aladdin Biochemical Technology Co., Ltd.; cat. no. P113150). The blood samples were randomly divided into four groups as follows: Control, high concentration of $\mathrm{CO}_{2}(\mathrm{HC})$, hypoxia, and hypoxia $++\mathrm{HC}$ groups. The control group was exposed to $5 \% \mathrm{CO}_{2}+20 \% \mathrm{O}_{2}$. The $\mathrm{HC}$ group was exposed to $10 \% \mathrm{CO}_{2}$ $+20 \% \mathrm{O}_{2}$. The hypoxia group was exposed to $5 \% \mathrm{CO}_{2}+$ $0.2 \% \mathrm{O}_{2}$. The hypoxia $+\mathrm{HC}$ group was exposed to $10 \% \mathrm{CO}_{2}+$ $0.2 \% \mathrm{O}_{2}$. These concentrations $\left(0.2 \% \mathrm{O}_{2}\right.$ and $\left.10 \% \mathrm{CO}_{2}\right)$ were used to maintain the $\mathrm{PO}_{2}$ of the medium at $\sim 60 \mathrm{mmHg}$ and the $\mathrm{pH}$ at 7.20-7.25. The $\mathrm{PO}_{2}, \mathrm{PCO}_{2}$ and $\mathrm{pH}$ of the medium were measured by a Blood Gas/Electrolyte Analyzer (Model 5700; Werfen Corporation).

$I L-1 \beta$ evaluation by ELISA in vitro and in vivo. The levels of IL-1 $\beta$ were evaluated using ELISA kits (applied to human blood cultures, cat. no. ab100562; applied to rat blood, cat. no. ab100768; Abcam) following the manufacturers' instructions. Briefly, the samples and standards were added to the plate wells coated by IL-1 $\beta$ antibodies labeled with horseradish peroxidase (HRP). Subsequently, a TMB substrate solution was pipetted to the wells. Then, stop buffer was added, and the OD was measured spectrophotometrically at a wavelength of $450 \mathrm{~nm}$. The concentration of IL-1 $\beta$ in the samples was determined by comparing the OD of the samples to the standard curve.

Primary cultures of rat brain capillary endothelial cells (RBECs). Primary cultures of RBECs were prepared as previously described (22-24). Briefly, the gray matter was isolated from the brain of 3-week-old Sprague-Dawley rats. The gray matter was minced into tiny particles, digested with DMEM containing collagenase type $2(1 \mathrm{mg} / \mathrm{ml})$, gentamycin $(50 \mu \mathrm{g} / \mathrm{ml})$, and $300 \mu \mathrm{l}$ DNase $(15 \mu \mathrm{g} / \mathrm{ml})$ at $37^{\circ} \mathrm{C}$ for $1.5 \mathrm{~h}$, then neutralized with bovine serum albumin (Calbiochem-Novabiochem Corp.), and finally centrifuged at $1,000 \mathrm{x} \mathrm{g}$ at $4^{\circ} \mathrm{C}$ for $20 \mathrm{~min}$. The cells were further digested in DMEM containing collagenase-dispase $(1 \mathrm{mg} / \mathrm{ml})$ and DNase $(6.7 \mu \mathrm{g} / \mathrm{ml})$ for 
$1 \mathrm{~h}$ at $37^{\circ} \mathrm{C}$. Microvessel endothelial cell clusters were separated on a 33\% continuous Percoll gradient, then collected and washed twice with DMEM before plating into collagen type IV- and fibronectin-coated dishes. RBECs were cultured in DMEM/F12 supplemented with $10 \%$ plasma-derived serum, heparin $(100 \mu \mathrm{g} / \mathrm{ml})$, basic fibroblast growth factor $(1.5 \mathrm{ng} / \mathrm{ml})$, transferrin $(5 \mu \mathrm{g} / \mathrm{ml})$, insulin $(5 \mu \mathrm{g} / \mathrm{ml})$, sodium selenite $(5 \mathrm{ng} / \mathrm{ml})$, puromycin $(4 \mu \mathrm{g} / \mathrm{ml})$ and gentamycin $(50 \mu \mathrm{g} / \mathrm{ml})\left(\mathrm{RBEC}\right.$ medium I) at $37^{\circ} \mathrm{C}$ in a humidified incubator with 5\% $\mathrm{CO}_{2} / 95 \%$ air for 2 days. On the following day, RBECs were cultured in RBEC medium II (RBEC medium I without puromycin). The medium was changed every other day from the 4th day onwards. The RBECs were randomly divided into four groups as follows: Control, IL-1 $\beta$, IL-1 $\beta+$ IL-1 receptor antagonist (IL-1Ra), and IL-1Ra groups. The control group was treated with $0.01 \mathrm{M}$ PBS. The IL-1 $\beta$ group was treated with IL-1 $\beta$ (40 ng/ml; MedChemExpress; cat. no. HY-P7028). The IL-1 $\beta$ + IL-1Ra group was treated with IL-1 $\beta(40 \mathrm{ng} / \mathrm{ml})$ and IL-1Ra (40 ng/ml; MedChemExpress; cat. no. HY-P7029). The IL-1Ra group was treated with IL-1Ra (40 ng/ml) (25).

Western blotting. Total proteins from the hippocampal tissue samples and RBECs ( $\mathrm{n}=4$ for each group) were extracted using a Total Protein Extraction kit (BestBio; cat. no. BB-3101-100T). Equal amounts $(40 \mu \mathrm{g})$ of proteins from each sample were separated in a $10 \%$ SDS-PAGE gel and transferred to PVDF membranes (EMD Millipore), which were then blocked with $5 \%$ non-fat milk for $1 \mathrm{~h}$ at room temperature. Subsequently, the membranes were incubated overnight at $4^{\circ} \mathrm{C}$ with primary antibodies against the following target proteins: IL-1R1 (1:1,000, Abcam; cat. no. ab106278), ZO-1 (1:1,000; Invitrogen; Thermo Fisher Scientific, Inc.; cat. no. SL258826), occludin (1:1,000; Abcam; cat. no. Ab216327), claudin-5 (1:1,000; Abbkine Scientific Co., Ltd.; cat. no. Abp50990), t-IRAK-1 (1:1,000; Abcam; cat. no. ab238) and p-IRAK-1 (1:1,000; Abcam; cat. no. ab218130). On the following day, HRP-labeled goat anti-rabbit antibody (1:3,000; Cell Signaling Technology, Inc.; cat. no. 7074S) was added and the membranes were incubated for $2 \mathrm{~h}$ at $4^{\circ} \mathrm{C}$. The immunoblots were visualized using a chemiluminescence kit (Bioworld Technology, Inc.; cat. no. AC36131), and detected by an imaging densitometer (ImageQuant LAS 500, GE Healthcare Bio-Sciences AB). The gray value was quantified using FluorChem 8900 software (version 4.0.1, Alpha Innotech Corporation). $\beta$-actin was used as the control. The relative density was calculated through dividing the gray value of $\beta$-actin by that of the target protein. Both the target protein and $\beta$-actin were from the same lane of the same membrane.

Double immunofluorescence labeling. In vivo, the rats were anesthetized with $2 \%$ pentobarbital sodium $(30 \mathrm{mg} / \mathrm{kg}$ by intraperitoneal injection) and transcardially perfused with saline and $4 \%$ paraformaldehyde at $3 \mathrm{~h}$ after ventilation. The brains were harvested and post-fixed overnight at $4^{\circ} \mathrm{C}$ in $4 \%$ paraformaldehyde. Subsequently, the tissue samples were dehydrated in graded sucrose and cut into $10-\mu \mathrm{m}$ sections. The sections were blocked in 5\% normal donkey serum (Abbkine Co., Ltd. cat. no. BMS0140) for $0.5 \mathrm{~h}$ at room temperature. In vitro, the coverslips with adherent RBECs were fixed with $4 \%$ paraformaldehyde for $20 \mathrm{~min}$ at room temperature at $24 \mathrm{~h}$ after treatment. The coverslips were blocked in 5\% normal donkey serum for $0.5 \mathrm{~h}$ at room temperature sequentially.

Subsequently, the sections/coverslips were incubated overnight at $4^{\circ} \mathrm{C}$ with the following primary antibodies: IL-1R1 (1:100, Abcam; cat. no. ab106278), ZO-1 (1:100; Invitrogen; Thermo Fisher Scientific Inc.; cat. no. SL258826), occludin (1:100; Abcam; cat. no. Ab216327), claudin-5 (1:100; Abbkine Scientific Co., Ltd.; cat. no. Abp50990), and CD31 (1:100; Abcam; cat. no. Ab24590). The sections/coverslips were washed on the following day, the secondary antibodies Alexa Fluor $^{\circledR} 549$ goat anti-rabbit IgG $(\mathrm{H}+\mathrm{L})(1: 100$; Invitrogen; Thermo Fisher Scientific Inc.; cat. no. ATRJN1301) and Alexa Fluor $^{\circledR} 488$ goat anti-mouse IgG (1:100; Invitrogen; Thermo Fisher Scientific Inc.; cat. no. ATRMR2301) were added, and the sections/coverslips were incubated for $1 \mathrm{~h}$ at room temperature. Finally, the sections/coverslips were mounted using fluorescent mounting medium with DAPI (Sigma-Aldrich; Merck KGaA; cat. no. SLBW4468) and examined using a fluorescence microscope (DP73, Olympus Corporation). At a magnification of $x 400$. Four fields of view per section/coverslip were examined in each group.

Statistical analysis. The statistical analysis was performed using SPSS v.19.0 (IBM Corp.). All values are expressed as mean \pm standard deviation. Student's t-test was used to analyze the data of two-group univariate-factor measurements. One-way analysis of variance (ANOVA) was used to analyze the data of 3 or more group univariate-factor measurements followed by Tukey's post hoc test. Repeated measures ANOVA was used to analyze the repeated measurement data. Factorial ANOVA was used for the interaction effects. When an interaction was examined, simple effects analyses were evaluated. $\mathrm{P}<0.05$ was considered to indicate statistically significant differences.

\section{Results}

$\mathrm{PO}_{2}, \mathrm{PCO}_{2}$ and $p H$ levels in the arterial blood of the rats. The $\mathrm{PO}_{2}$ levels in the arterial blood were maintained at $\sim 60 \mathrm{mmHg}$ in the $\mathrm{HH}$ and hypoxemia groups, and were significantly decreased compared with those in the Sham group (HH vs. Sham: $\mathrm{P}<0.01$; hypoxemia vs. Sham: $\mathrm{P}<0.01)$ and the hypercapnia group ( $\mathrm{HH}$ vs. hypercapnia: $\mathrm{P}<0.01$; hypoxemia vs. hypercapnia: $\mathrm{P}<0.01)$. The $\mathrm{PO}_{2}$ levels of the $\mathrm{HH}$ group were not significantly different when compared with those of the hypoxemia group ( $\mathrm{P}>0.05$; Fig. 1A-a). The $\mathrm{PCO}_{2}$ levels in the arterial blood were maintained at $60-70 \mathrm{mmHg}$ in the $\mathrm{HH}$ and hypercapnia groups, and were significantly higher compared with those in the Sham group (HH vs. Sham: $\mathrm{P}<0.01$; hypercapnia vs. Sham: $\mathrm{P}<0.01)$ and the hypoxemia group $(\mathrm{HH}$ vs. hypoxemia: $\mathrm{P}<0.01$; hypercapnia vs. hypoxemia: $\mathrm{P}<0.01)$. There was no significant difference between the $\mathrm{HH}$ and hypercapnia groups in the $\mathrm{PCO}_{2}$ levels ( $\mathrm{P}>0.05$; Fig. 1A-b). The $\mathrm{pH}$ of the arterial blood was maintained at 7.20-7.25 in the $\mathrm{HH}$ and hypercapnia groups, and was significantly lower compared with that in the Sham group (HH vs. Sham: $\mathrm{P}<0.01$; hypercapnia vs. Sham: $\mathrm{P}<0.01)$ and the hypoxemia group ( $\mathrm{HH}$ vs. hypoxemia: $\mathrm{P}<0.01$; hypercapnia vs. hypoxemia: $\mathrm{P}<0.01)$. There was no significant difference in the $\mathrm{pH}$ levels between the $\mathrm{HH}$ and hypercapnia groups ( $\mathrm{P}>0.05$; Fig. $1 \mathrm{~A}-\mathrm{c}$ ). 
A

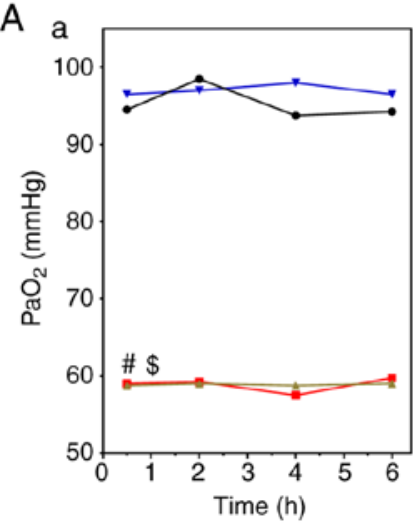

B

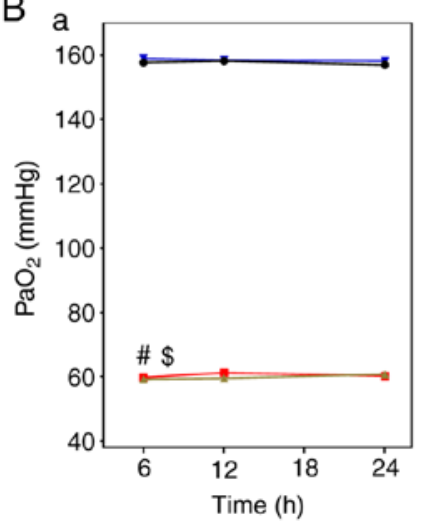

b

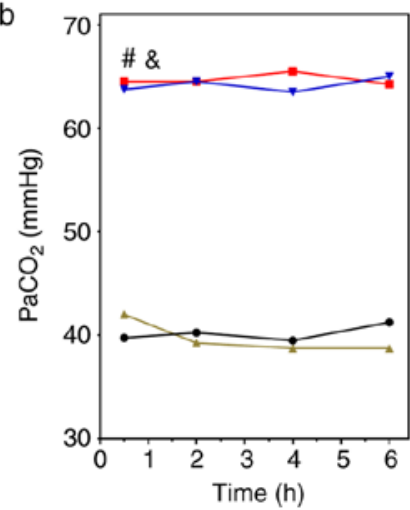

b

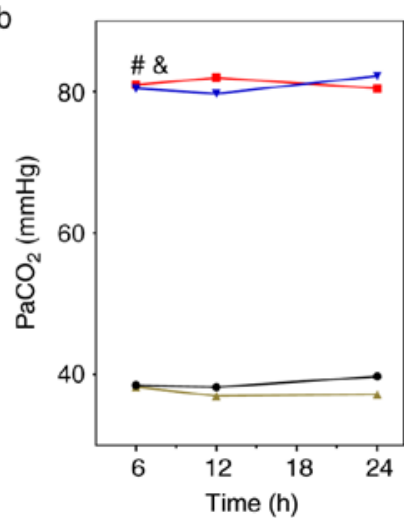

C

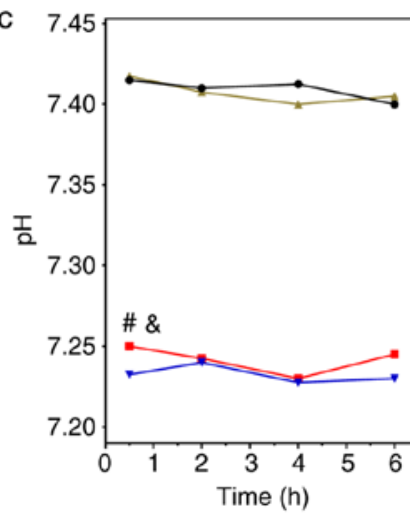

C

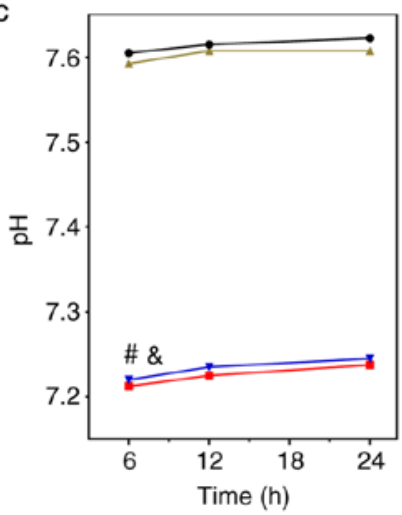

$\rightarrow$ Sham

- Hypercapnia

- Hypoxemia

$=\mathrm{HH}$

Figure 1. $\mathrm{PO}_{2}, \mathrm{PCO}_{2}$ and $\mathrm{pH}$ levels in the arterial blood of rats and whole-blood culture medium (n=4). (A-a) $16 \% \mathrm{O}_{2}$ treatment decreased the $\mathrm{PO}_{2}$ levels of the arterial blood in the $\mathrm{HH}$ and hypoxemia groups to $\sim 60 \mathrm{mmHg}$. The $\mathrm{PO}_{2}$ levels were significantly lower compared with those in the hypercapnia group $\left({ }^{\$} \mathrm{P}<0.01\right)$ and the Sham group $\left({ }^{*} \mathrm{P}<0.01\right)$. (A-b) $5 \% \mathrm{CO}_{2}$ treatment increased the $\mathrm{PCO}_{2}$ levels of the arterial blood in the $\mathrm{HH}$ and hypercapnia groups to $60-70 \mathrm{mmHg}$. The $\mathrm{PCO}_{2}$ levels were significantly higher compared with those in the hypoxemia group $\left({ }^{\circledR} \mathrm{P}<0.01\right)$ and the Sham group $\left({ }^{*} \mathrm{P}<0.01\right) .(\mathrm{A}-\mathrm{c}) 5 \% \mathrm{CO}_{2}$ treatment decreased the $\mathrm{pH}$ of the arterial blood in the $\mathrm{HH}$ and hypercapnia groups to 7.2-7.25. The $\mathrm{pH}$ levels were significantly lower compared with those in the hypoxemia group $\left({ }^{\circledR} \mathrm{P}<0.01\right)$ and the Sham group $\left({ }^{*} \mathrm{P}<0.01\right)$. (B-a) $0.02 \% \mathrm{O}_{2}$ treatment decreased the $\mathrm{PO}_{2}$ levels of the medium in the hypoxia $+\mathrm{HC}$ and hypoxia groups to $\sim 60 \mathrm{mmHg}$. The $\mathrm{PO}_{2}$ levels were significantly lower compared with those in the $\mathrm{HC}$ group $\left({ }^{\mathrm{S}} \mathrm{P}<0.01\right)$ and the control group $\left({ }^{\sharp} \mathrm{P}<0.01\right)$. (B-b) $10 \% \mathrm{CO}{ }_{2}$ treatment increased the $\mathrm{PCO}_{2}$ levels of the medium in the hypoxia $+\mathrm{HC}$ and $\mathrm{HC}$ groups to $\sim 80 \mathrm{mmHg}$. The $\mathrm{PCO}_{2}$ levels were significantly higher compared with those in the hypoxia group $\left({ }^{\circledR} \mathrm{P}<0.01\right)$ and the control group $\left({ }^{*} \mathrm{P}<0.01\right)$. $(\mathrm{B}-\mathrm{c}) 5 \% \mathrm{CO}_{2}$ treatment decreased the $\mathrm{pH}$ of the medium in the hypoxia $+\mathrm{HC}$ and $\mathrm{HC}$ groups to 7.2-7.25. The $\mathrm{pH}$ levels were significantly lower compared with those in the hypoxia group $\left({ }^{\circledR} \mathrm{P}<0.01\right)$ and the control group $\left({ }^{\#} \mathrm{P}<0.01\right)$. HH, hypercapnia + hypoxemia; $\mathrm{HC}$, high concentration of $\mathrm{CO}_{2}$.

$\mathrm{PO}_{2}, \mathrm{PCO}_{2}$ and $\mathrm{pH}$ levels in the whole-blood culture medium. The $\mathrm{PO}_{2}$ levels were maintained at $\sim 60 \mathrm{mmHg}$ in the hypoxia $+\mathrm{HC}$ and hypoxia groups, and were significantly decreased compared with those in the control group (hypoxia $+\mathrm{HC}$ vs. control: $\mathrm{P}<0.01$; hypoxia vs. control: $\mathrm{P}<0.01)$ and the HC group (hypoxia + HC vs. HC: $\mathrm{P}<0.01$; hypoxia vs. HC: $\mathrm{P}<0.01$ ). The $\mathrm{PO}_{2}$ levels of the hypoxia $+\mathrm{HC}$ group were not significantly different when compared with those of the hypoxia group ( $\mathrm{P}>0.05$; Fig. 1B-a). The $\mathrm{PCO}_{2}$ levels were maintained at $\sim 80 \mathrm{mmHg}$ in the hypoxia $+\mathrm{HC}$ and $\mathrm{HC}$ groups, and were significantly higher compared with those in the control group (hypoxia + HC vs. control: $\mathrm{P}<0.01$; HC vs. control: $\mathrm{P}<0.01$ ) and the hypoxia group (hypoxia $+\mathrm{HC}$ vs. hypoxia: $\mathrm{P}<0.01$; $\mathrm{HC}$ vs. hypoxia: $\mathrm{P}<0.01)$. There was no significant difference in the $\mathrm{PCO}_{2}$ levels between the hypoxia $+\mathrm{HC}$ and $\mathrm{HC}$ groups ( $\mathrm{P}>0.05$; Fig. 1B-b). The $\mathrm{pH}$ was maintained at 7.20-7.25 in the hypoxia $+\mathrm{HC}$ and $\mathrm{HC}$ groups, and was significantly decreased compared with that in the control group (hypoxia $+\mathrm{HC}$ vs. control: $\mathrm{P}<0.01$; $\mathrm{HC}$ vs. control: $\mathrm{P}<0.01)$ and the hypoxia group (hypoxia $+\mathrm{HC}$ vs. hypoxia: $\mathrm{P}<0.01$; $\mathrm{HC}$ vs. hypoxia: $\mathrm{P}<0.01$ ). There was no significant difference in the $\mathrm{pH}$ levels between the hypoxia $+\mathrm{HC}$ and $\mathrm{HC}$ groups $(\mathrm{P}>0.05$; Fig. 1B-c).
Hypercapnia increases $I L-1 \beta$ expression in the blood of hypoxemic rats. An interaction effect was observed between hypoxia treatment and hypercapnia treatment $(\mathrm{P}<0.01$; Fig. 2A). Simple effects analyses found increased IL-1 $\beta$ expression in the hypoxemia group $(\mathrm{P}<0.01)$, but not in the hypercapnia group $(\mathrm{P}>0.05)$ compared with the Sham group. The HH group exhibited the highest expression levels of IL-1 $\beta$ when compared with the hypoxemia group $(\mathrm{P}<0.01)$ and the hypercapnia group $(\mathrm{P}<0.01$; Fig. $2 \mathrm{~B})$.

Treatment with $10 \% \mathrm{CO}_{2}$ increases $\mathrm{IL}-1 \beta$ expression in hypoxic whole-blood cultures. An interaction effect was observed between $10 \% \mathrm{CO}_{2}$ treatment and $0.2 \% \mathrm{O}_{2}$ treatment $(\mathrm{P}<0.01$; Fig. 2C). Simple effects analyses found increased IL-1 $\beta$ expression in the hypoxia group $(\mathrm{P}<0.01)$, but not in the HC group $(\mathrm{P}>0.05)$ compared with the control group. The hypoxia $+\mathrm{HC}$ group exhibited the highest expression levels of IL-1 $\beta$ compared with the hypoxia group $(\mathrm{P}<0.01)$ and the $\mathrm{HC}$ group ( $\mathrm{P}<0.01$; Fig. 2D).

Hypercapnia increases IL-1RI expression in the cerebrovascular endothelial cells of hypoxemic rats. An interaction effect 
A
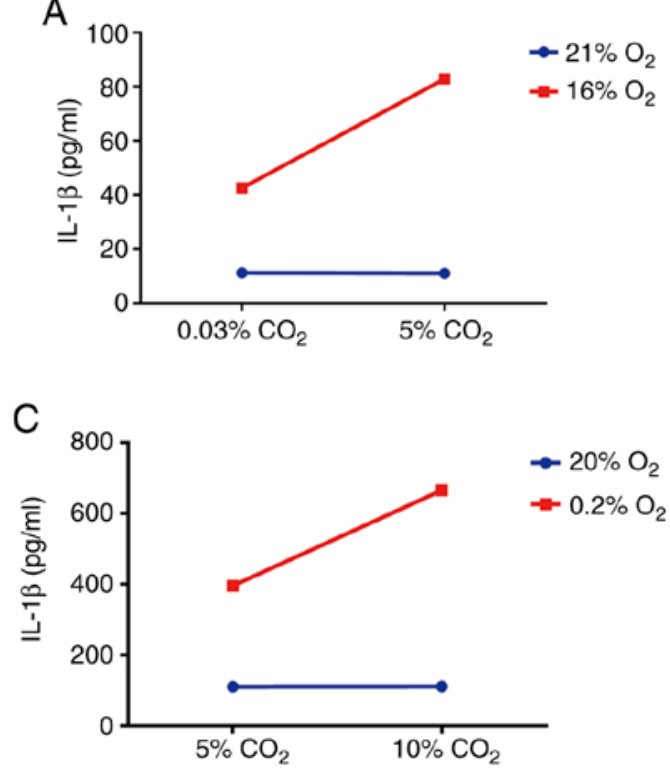

B
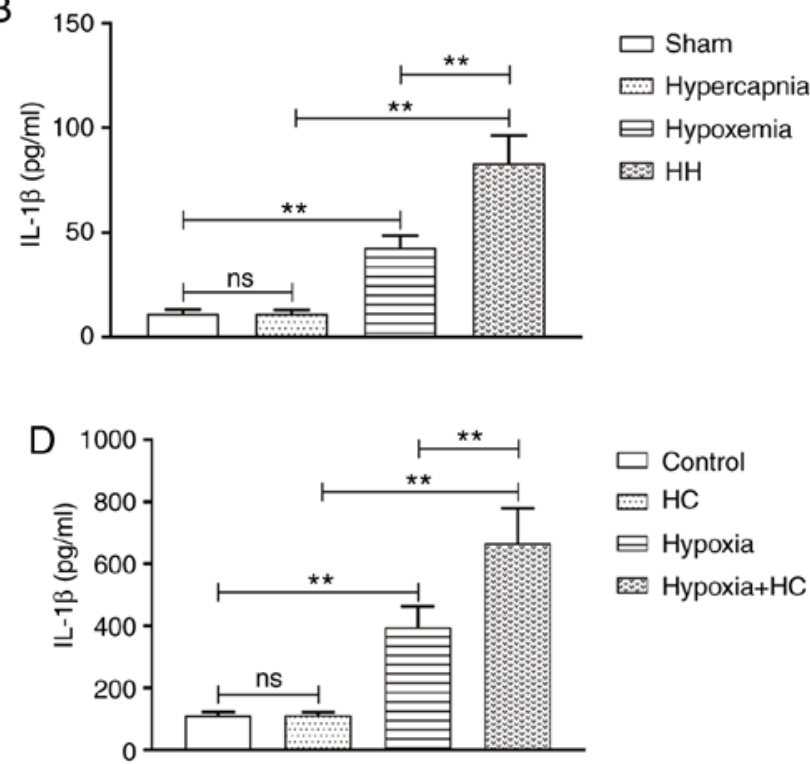

$\square$ Control

ㅁ. HC

Е Hypoxia

Hypoxia+HC

Figure 2. Hypercapnia increased the expression of IL-1 $\beta$ in the hypoxic blood in vivo and in vitro (n=4). (A) There was an interaction effect between hypoxia treatment and hypercapnia treatment $(\mathrm{P}<0.01)$. (B) Simple effects analyses revealed increased IL- $1 \beta$ expression in the hypoxemia group $\left({ }^{* *} \mathrm{P}<0.01\right)$, but not in the hypercapnia group $(\mathrm{P}>0.05)$ compared with the Sham group. The expression levels of IL-1 $\beta$ were the highest in the HH group in comparison with the hypoxemia group $\left({ }^{* *} \mathrm{P}<0.01\right)$ and the hypercapnia group $\left({ }^{* *} \mathrm{P}<0.01\right)$. (C) There was an interaction effect between $0.2 \% \mathrm{O}_{2}$ treatment and $10 \% \mathrm{CO}_{2}$ treatment. (D) Simple effects analyses revealed increased IL-1 $\beta$ expression in the hypoxia group $\left({ }^{* *} \mathrm{P}<0.01\right)$, but not in the HC group (P>0.05) compared with the control group. The expression levels of IL-1 $\beta$ were the highest in the hypoxia $+\mathrm{HC}$ group compared with the hypoxia group $\left({ }^{* *} \mathrm{P}<0.01\right)$ and the $\mathrm{HC}$ group $\left({ }^{* *} \mathrm{P}<0.01\right)$. The concentrations of $\mathrm{O}_{2}$ and $\mathrm{CO}_{2}$ in the air were 21 and $0.03 \%$, respectively. IL-1 $\beta$, interleukin-1 $\beta$; HH, hypercapnia + hypoxemia; ns, non-significant; HC, high concentration of carbon dioxide.

was observed between hypoxia treatment and hypercapnia treatment $(\mathrm{P}<0.05$; Fig. 3B). Simple effects analyses found increased IL-1R1 expression in the hypoxemia group $(\mathrm{P}<0.05)$, but not in the hypercapnia group $(\mathrm{P}>0.05)$ when compared with the Sham group. The expression levels of IL-1R1 were the highest in the HH group compared with those in the hypoxemia group $(\mathrm{P}<0.01)$ and the hypercapnia group $(\mathrm{P}<0.01$; Fig. $3 \mathrm{C})$. Double immunofluorescence was used to examine IL-1R1 expression in cerebrovascular endothelial cells. Enhanced IL-1R1 immunofluorescence was observed in the hypoxemia group, but not in the hypercapnia group compared with the Sham group. The HH group exhibited the most intense IL-1R1 fluorescence compared with the hypoxemia and hypercapnia groups (Fig. 3D).

$I L-1 \beta$ treatment increases IL-1RI and $p$-IRAK-1 expression in $R B E C s$. IL-1R1 expression was increased in the IL-1 $\beta$ group compared with that in the control group ( $\mathrm{P}<0.01$; Fig. $4 \mathrm{~B})$. Double immunofluorescence was used to examine IL-1R1 expression in RBECs. Enhanced IL-1R1 immunofluorescence was observed in the IL- $1 \beta$ group compared with that in the Sham group (Fig. 4C). Increased p-IRAK-1 expression was observed in the IL-1 $\beta$ group compared with that in the control group $(\mathrm{P}<0.01)$. The protein expression of $\mathrm{p}-\mathrm{IRAK}-1$ was significantly suppressed with IL-1Ra pretreatment $(\mathrm{P}<0.05$; Fig. 4E).

Hypercapnia decreases tight junctional protein expression in the cerebrovascular endothelial cells of hypoxemic rats. Significant interaction effects were observed between hypoxia treatment and hypercapnia treatment (ZO-1: $\mathrm{P}<0.05$; occludin: $\mathrm{P}<0.05$; and claudin-5: $\mathrm{P}<0.05$; Fig. 5B-D). Simple effects analyses found decreased expression of tight junctional proteins in the hypoxemia group (ZO-1: $\mathrm{P}<0.01$; occludin: $\mathrm{P}<0.01$; and claudin-5: $\mathrm{P}<0.05)$, but not in the hypercapnia group (ZO-1: $\mathrm{P}>0.05$; occludin: $\mathrm{P}>0.05$; and claudin-5: $\mathrm{P}>0.05$ ) compared with the Sham group. The HH group exhibited the lowest expression levels of tight junctional proteins in comparison with the hypoxemia group (ZO-1: $\mathrm{P}<0.01$; occludin: $\mathrm{P}<0.05$; and claudin-5: $\mathrm{P}<0.05)$ and the hypercapnia group $(\mathrm{ZO}-1$ : $\mathrm{P}<0.01$; occludin: $\mathrm{P}<0.01$; and claudin-5: $\mathrm{P}<0.01$; Fig. $5 \mathrm{E}$ ). Double immunofluorescence was used to examine tight junctional protein expression in cerebrovascular endothelial cells (Figs. S1-S3). Reduced ZO-1, occludin and claudin-5 immunofluorescence was observed in the hypoxemia group, but not in the hypercapnia group, when compared with the Sham group. The HH group exhibited the weakest ZO-1, occludin and claudin-5 fluorescence compared with the hypoxemia and hypercapnia groups.

$I L-1 \beta$ treatment decreases tight junctional protein expression in RBECs. The IL-1 $\beta$ group exhibited decreased tight junctional protein expression compared with the control group ( $\mathrm{ZO}-1$ : $\mathrm{P}<0.01$; occludin: $\mathrm{P}<0.01$; and claudin-5: $\mathrm{P}<0.01)$. The tight junctional protein expression was significantly upregulated with IL-1Ra pretreatment (ZO-1: $\mathrm{P}<0.01$; occludin: $\mathrm{P}<0.01$; and claudin-5: $\mathrm{P}<0.05$; Fig. 6). Double immunofluorescence was used to examine tight junctional protein expression in RBECs (Figs. S4-S6). Reduced ZO-1, occludin and claudin-5 immunofluorescence was observed in the IL-1 $\beta$ group compared with that in the control group. Of note, $\mathrm{ZO}-1$, occludin and claudin-5 fluorescence was enhanced with IL-1Ra pretreatment in RBECs. 

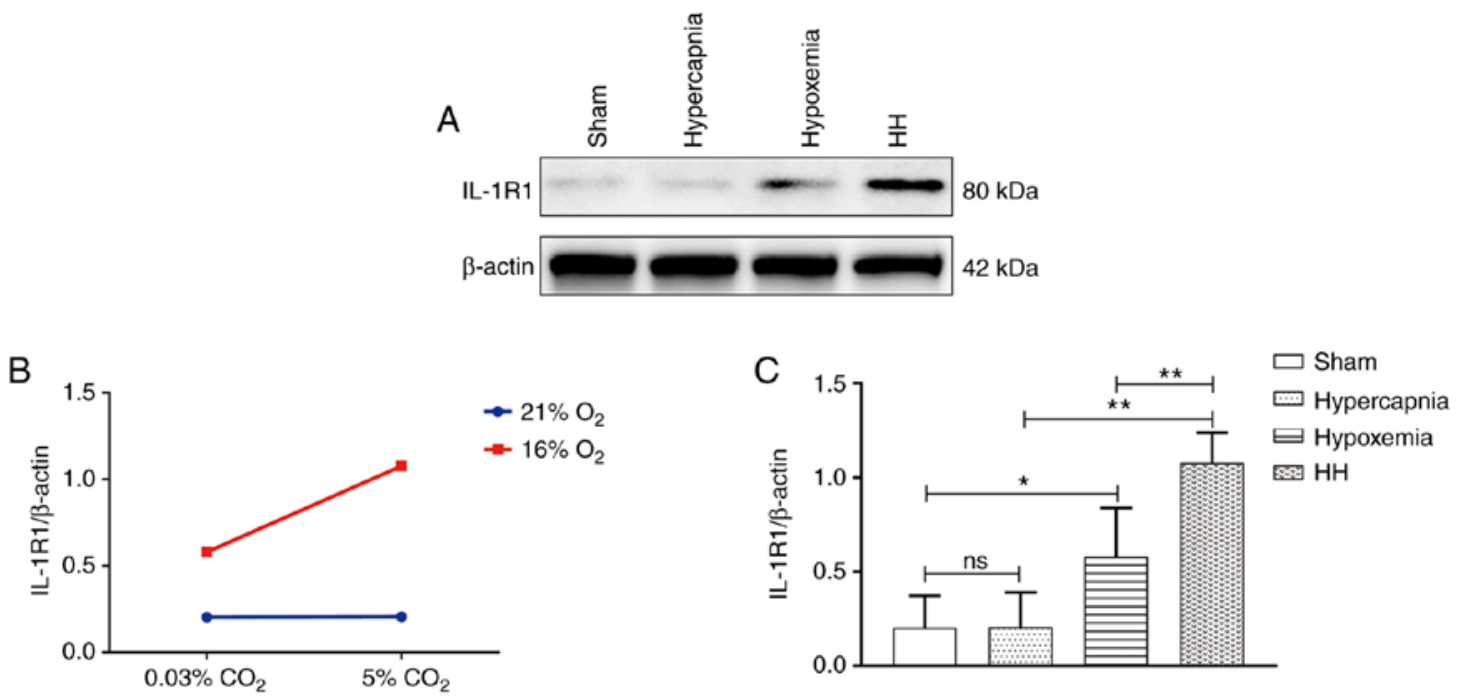

D

CD31/DAPI
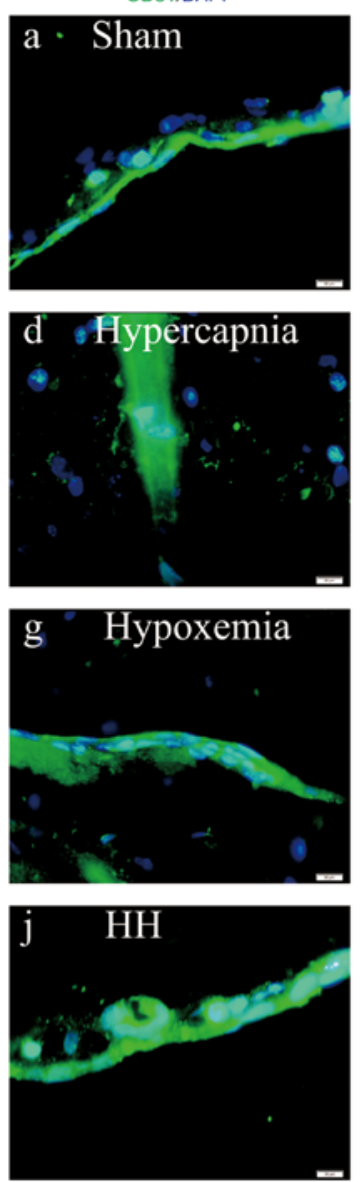
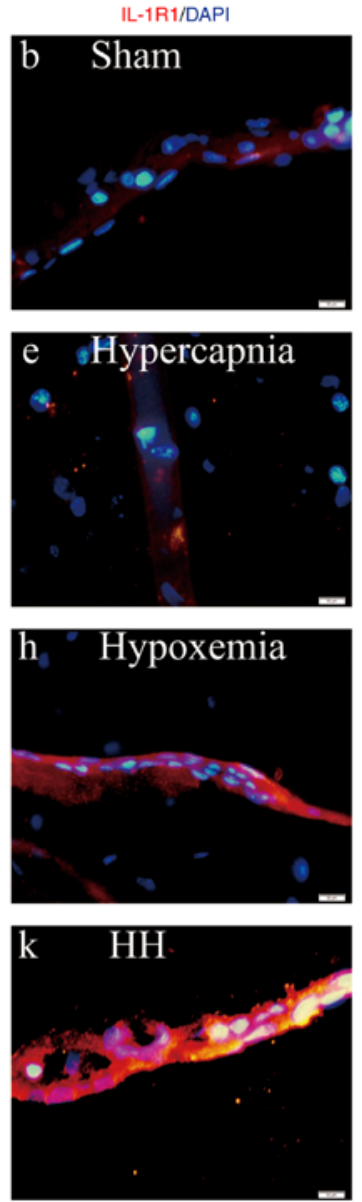
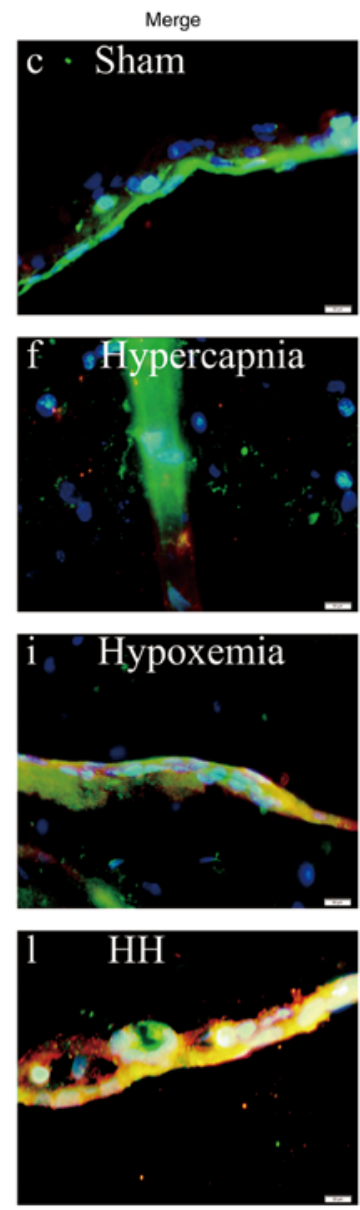

Figure 3. Hypercapnia increased IL-1R1 expression in the cerebrovascular endothelial cells of hypoxemic rats (n=4). (A) Immunoreactive bands of IL-1R1 $(80 \mathrm{kDa})$ and $\beta$-actin $(42 \mathrm{kDa})$. (B) There was an interaction effect between hypoxia treatment and hypercapnia treatment $(\mathrm{P}<0.05)$. (C) Simple effects analyses revealed increased IL-1R1 expression in the hypoxemia group ( $\mathrm{P}<0.05)$, but not in the hypercapnia group $(\mathrm{P}>0.05)$ compared with the Sham group. The $\mathrm{HH}$ group exhibited the highest expression levels of IL-1R1 when compared with the hypoxemia group $\left({ }^{* *} \mathrm{P}<0.01\right)$ and the hypercapnia group ( $\left.{ }^{* *} \mathrm{P}<0.01\right)$. (D) Immunofluorescence images showing the expression of CD31+ cerebrovascular endothelial cells (a, d, g and j, green), IL-1R1 (b, e, h and k, red), and the co-localization of IL-1R1 and cerebrovascular endothelial cells (c, f, i and 1). Of note, enhanced IL-1R1 immunofluorescence was evident in the hypoxemia group, but not in the hypercapnia group, compared with the Sham group. The HH group emitted the strongest IL-1R1 fluorescence as compared with the hypoxemia and hypercapnia groups. Scale bars (a-1): $50 \mu \mathrm{m}$. The concentrations of $\mathrm{O}_{2}$ and $\mathrm{CO}_{2}$ in the air were 21 and $0.03 \%$, respectively. IL-1R, interleukin-1 receptor; HH, hypercapnia + hypoxemia; ns, non-significant.

Hypercapnia increases BBB permeability to EB in hypoxemic rats. An interaction effect was observed between hypoxia treatment and hypercapnia treatment $(\mathrm{P}<0.01 ;$ Fig. 7A). Simple effects analyses found increased extravasation of EB in the hypoxemia group $(\mathrm{P}<0.01)$, but not in the hypercapnia group $(\mathrm{P}>0.05)$ compared with the Sham group. The extravasation 
A

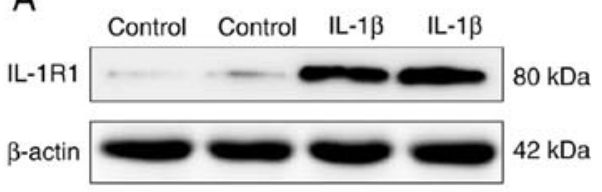

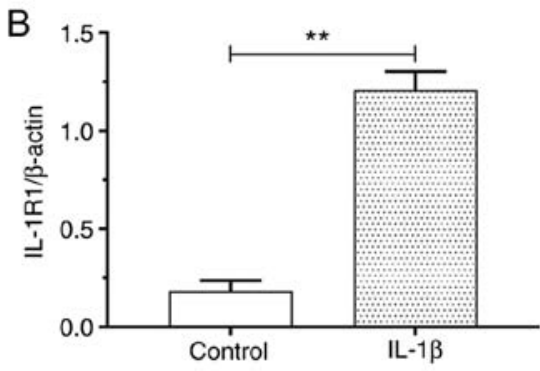

C
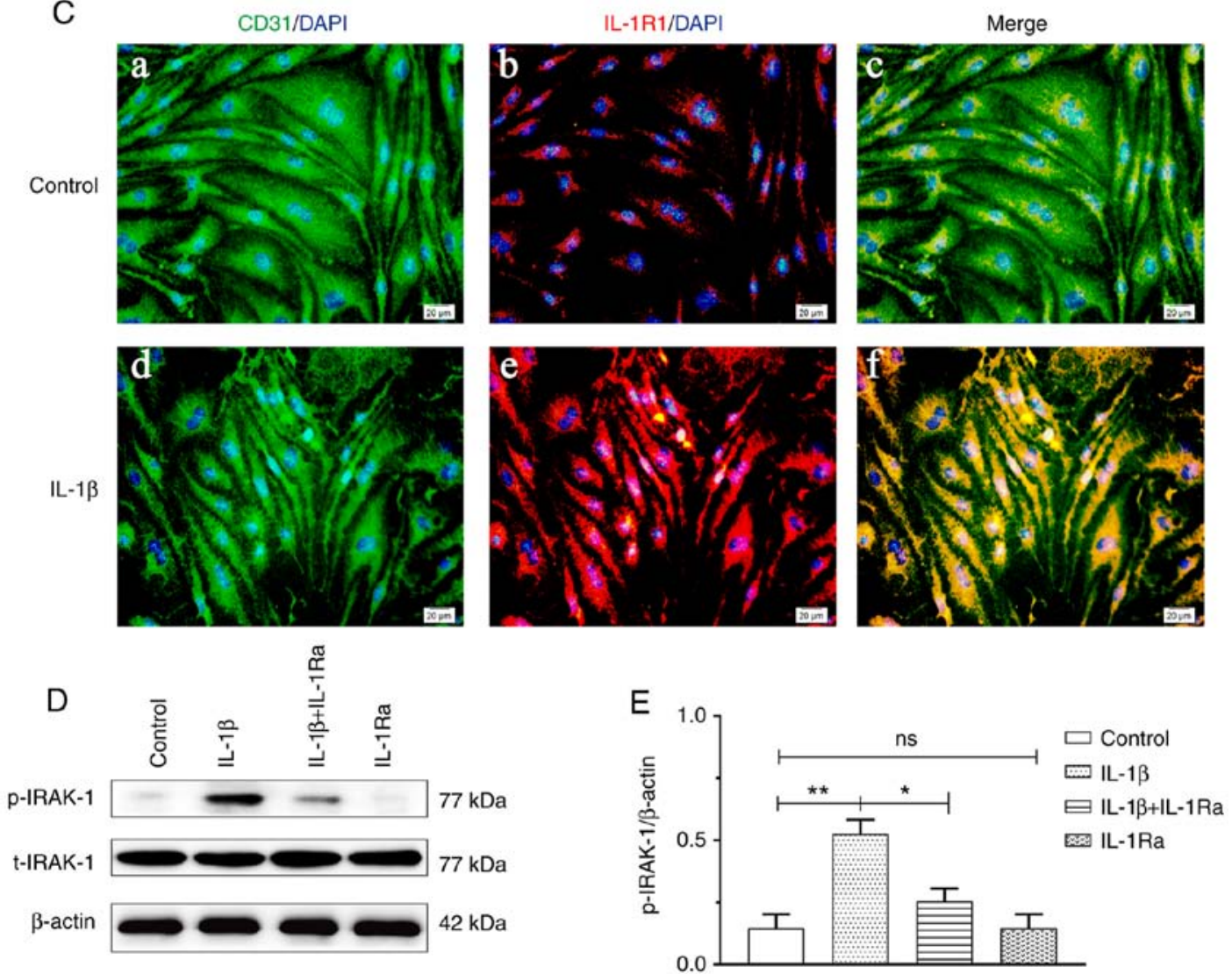

Figure 4. IL-1 $\beta$ treatment increased IL-1R1 and p-IRAK-1 expression in RBECs (n=4). (A) Immunoreactive bands of IL-1R1 (80 kDa) and $\beta$-actin (42 kDa). (B) The bar graph shows increased IL-1R1 expression in the IL-1 $\beta$ group compared with that in the control group $\left({ }^{* *} \mathrm{P}<0.01\right)$. (C) Immunofluorescence images showing the expression of CD31 ${ }^{+}$RBECs (a and d, green), IL-1R1 (b and e, red), and the co-localization of IL-1R1 and RBECs (c and f). Enhanced IL-1R1 immunofluorescence was evident in the IL-1 $\beta$ group compared with the control group. Scale bars (a-f): $10 \mu$ m. (D) Immunoreactive bands of p-RIAK-1 $(77 \mathrm{kDa}), \mathrm{t}-\mathrm{IRAK}-1(77 \mathrm{kDa})$ and $\beta$-actin $(42 \mathrm{kDa})$. (E) The bar graph shows increased p-IRAK-1 expression in the IL-1 $\beta$ group compared with the control group $\left({ }^{* *} \mathrm{P}<0.01\right)$. The protein expression of $\mathrm{p}-\mathrm{IRAK}-1$ was significantly suppressed with IL-1Ra treatment $\left({ }^{*} \mathrm{P}<0.05\right)$. RBECs, rat brain capillary endothelial cells; IL-1 $\beta$, interleukin-1 $\beta$; IL-1R, interleukin-1 receptor; IL-1Ra, interleukin-1 receptor antagonist; HC, high concentration of carbon dioxide; ns, non-significant.

of EB was the most prominent in the $\mathrm{HH}$ group compared with the hypoxemia group $(\mathrm{P}<0.01)$ and the hypercapnia group $(\mathrm{P}<0.01$; Fig. 7B).

\section{Discussion}

The present study demonstrated that hypercapnia could increase BBB permeability through inducing IL-1 $\beta$ overexpression in the blood of hypoxemic rats. Additionally, it was demonstrated that hypercapnia decreased tight junctional protein expression in hypoxic cerebrovascular endothelial cells via the IL-1R1/p-IRAK-1 pathway. This was further verified by the increased expression of tight junctional proteins in hypoxic cerebrovascular endothelial cells when the effects of IL-1 $\beta$ were blocked by IL-1Ra.
The present rat model of hypercapnia/hypoxemia was established as described in our previous study (6). In the Sham group, the rats were exposed to air when the ventilator settings were fixed. The $\mathrm{PaCO}_{2}$ levels of the rats were maintained at 35-45 mmHg, and the $\mathrm{PaO}_{2}$ levels were maintained at 90-100 mmHg. The normal range of human $\mathrm{PaCO}_{2}$ and $\mathrm{PaO}_{2}$ is 35-45 and 80-100 $\mathrm{mmHg}$, respectively, which are comparable between rats and humans. Treatment with $16 \% \mathrm{O}_{2}$ maintained the $\mathrm{PO}_{2}$ levels of the arterial blood at $\sim 60 \mathrm{mmHg}$, and $5 \% \mathrm{CO}_{2}$ treatment maintained the $\mathrm{PCO}_{2}$ levels of the arterial blood at $60-70 \mathrm{mmHg}$, with the $\mathrm{pH}$ levels at 7.20-7.25. In vitro, $0.02 \% \mathrm{O}_{2}$ treatment maintained the $\mathrm{PO}_{2}$ levels of whole-blood culture medium at $\sim 60 \mathrm{mmHg}$. The $\mathrm{PCO}_{2}$ was $\sim 80 \mathrm{mmHg}$, with the $\mathrm{pH}$ at 7.20-7.25 when treated with $10 \% \mathrm{CO}_{2}$. The rats were treated with $5 \% \mathrm{CO}_{2}$ and $10 \% \mathrm{CO}_{2}$ was used to treat human 

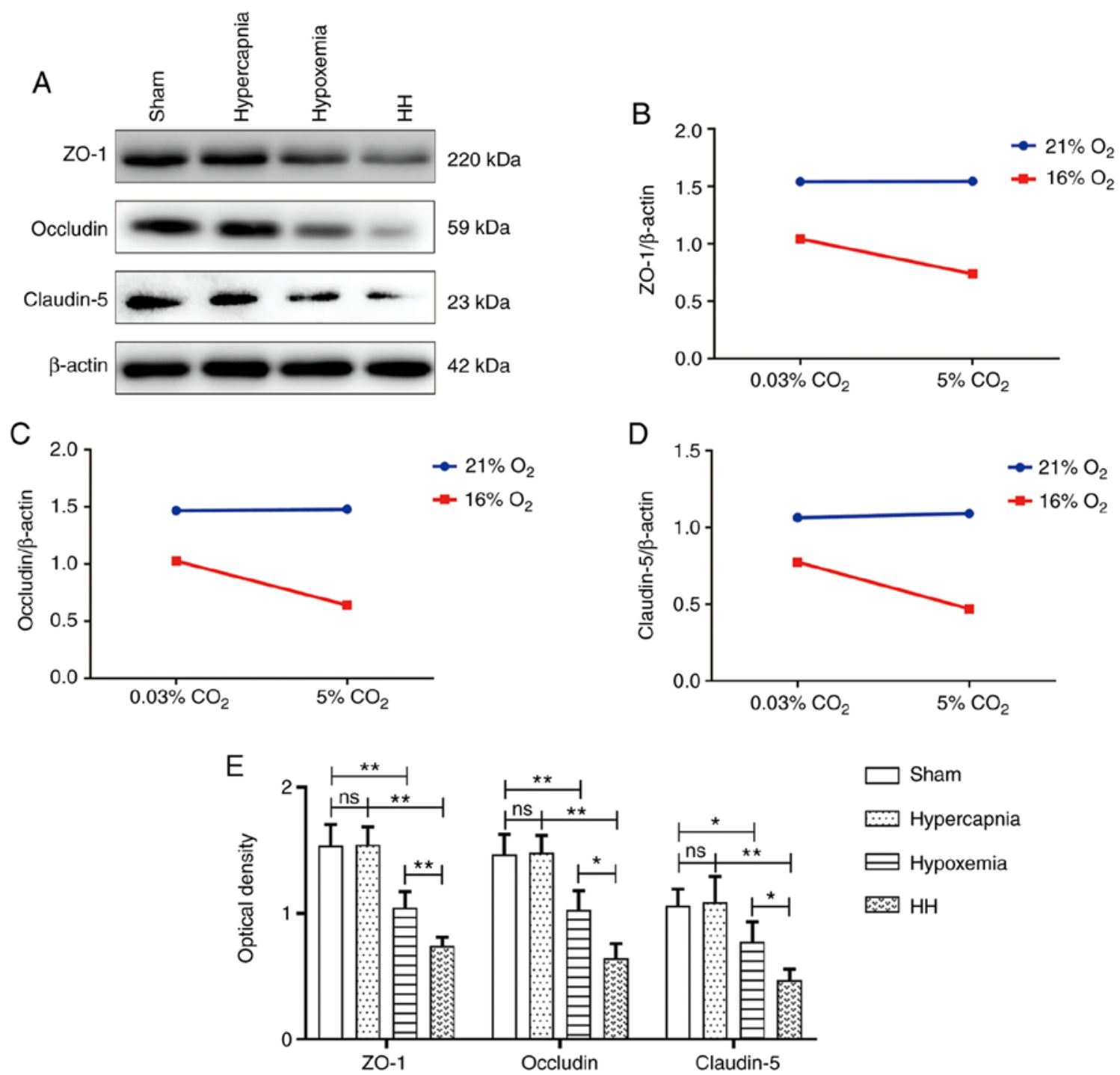

Figure 5. Hypercapnia decreased the expression of tight junctional proteins in the hypoxemic hippocampus (n=4). (A) Immunoreactive bands of ZO- $1(220 \mathrm{kDa})$, occludin $(59 \mathrm{kDa})$, claudin-5 $(23 \mathrm{kDa})$ and $\beta$-actin $(42 \mathrm{kDa})$. (B-D) There were interaction effects between hypoxia treatment and hypercapnia treatment (ZO-1: $\mathrm{P}<0.05$; occludin: $\mathrm{P}<0.05$; and claudin-5: $\mathrm{P}<0.05$ ). (E) Simple effects analyses revealed decreased tight junctional protein expression in the hypoxemia group (ZO-1: ${ }^{* *} \mathrm{P}<0.01$; occludin: ${ }^{* *} \mathrm{P}<0.01$; and claudin -5 : $\left.{ }^{*} \mathrm{P}<0.05\right)$, but not in the hypercapnia group (ZO-1: ns $\mathrm{P}>0.05$; occludin: ns $\mathrm{P}>0.05$; and claudin-5: ns $\mathrm{P}>0.05)$ compared with the Sham group. The expression levels of tight junctional proteins were the lowest in the HH group compared with the hypoxemia group (ZO-1: ${ }^{* *} \mathrm{P}<0.01$; occludin: ${ }^{*} \mathrm{P}<0.05$; and claudin-5: $\left.{ }^{*} \mathrm{P}<0.05\right)$ and the hypercapnia group $\left(Z \mathrm{O}-1:{ }^{* *} \mathrm{P}<0.01\right.$; occludin: ${ }^{* *} \mathrm{P}<0.01$; and claudin-5: $\left.{ }^{* *} \mathrm{P}<0.01\right)$. The concentrations of $\mathrm{O}_{2}$ and $\mathrm{CO}_{2}$ in the air were 21 and $0.03 \%$, respectively. $\mathrm{HH}$, hypercapnia + hypoxemia; ZO-1, zonula occludens-1; ns, non-significant.

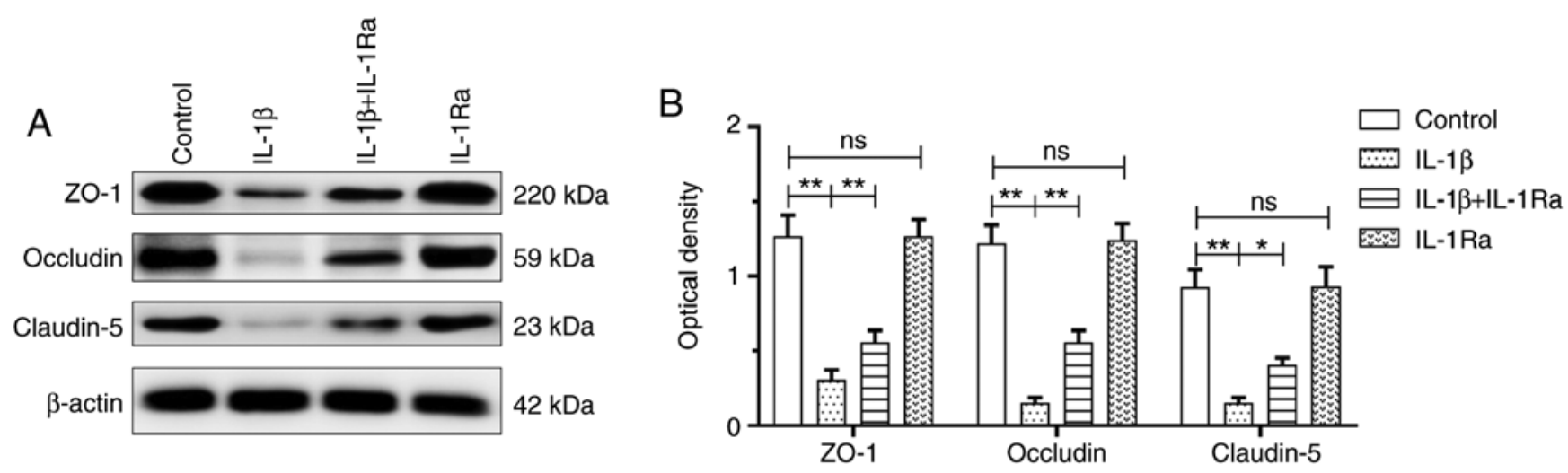

Figure 6. IL-1 $\beta$ treatment decreased the expression of tight junctional proteins in RBECs (n=4). (A) Immunoreactive bands of ZO-1 (220 kDa), occludin $(59 \mathrm{kDa})$, claudin-5 $(23 \mathrm{kDa})$ and $\beta$-actin $(42 \mathrm{kDa})$. (B) There was decreased tight junctional protein expression in the IL-1 $\beta$ group compared with the control group $\left(\mathrm{ZO}-1:{ }^{* * *} \mathrm{P}<0.01\right.$; occludin: ${ }^{* *} \mathrm{P}<0.01$; and claudin-5: $\left.{ }^{* *} \mathrm{P}<0.01\right)$. The expression of tight junctional proteins was significantly upregulated following IL-1Ra treatment (ZO-1: ${ }^{* *} \mathrm{P}<0.01$; occludin: ${ }^{* *} \mathrm{P}<0.01$; and claudin-5: $\left.{ }^{*} \mathrm{P}<0.05\right)$. RBECs, rat brain capillary endothelial cells; ZO-1, zonula occludens-1; IL-1 $\beta$, interleukin-1 $\beta$; IL-1Ra, interleukin-1 receptor antagonist; ns, non-significant. 

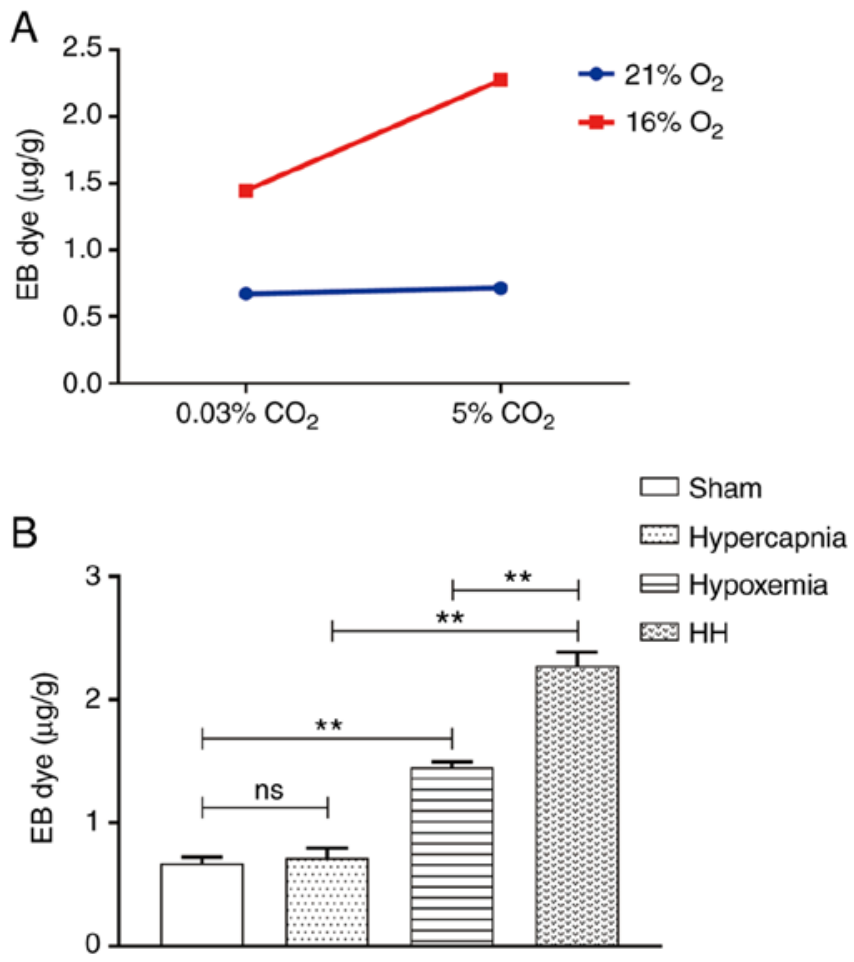

Figure 7. Hypercapnia enhanced blood-brain barrier permeability in hypoxemic rats $(n=4)$. (A) There was an interaction effect between hypoxia treatment and hypercapnia treatment $(\mathrm{P}<0.01)$. (B) Simple effects analyses revealed increased extravasation of $\mathrm{EB}$ in the hypoxemia group $\left({ }^{* *} \mathrm{P}<0.01\right)$, but not in the hypercapnia group $(\mathrm{P}>0.05)$ compared with the Sham group. The extravasation of EB was the most notable in the $\mathrm{HH}$ group compared with the hypoxemia group $\left({ }^{* *} \mathrm{P}<0.01\right)$ and the hypercapnia group $\left({ }^{* *} \mathrm{P}<0.01\right)$. The concentrations of $\mathrm{O}_{2}$ and $\mathrm{CO}_{2}$ in the air were 21 and $0.03 \%$, respectively. EB, Evans blue; HH group, hypercapnia + hypoxemia; ns, non-significant.

whole-blood cultures. Although the $\mathrm{CO}_{2}$ concentrations were different in vivo and in vitro, the $\mathrm{pH}$ levels were consistent with the changes of permissive hypercapnia in ARDS (26-29).

The results of the present study demonstrated that hypercapnia enhanced the expression of IL-1 $\beta$ in hypoxic rats and whole-blood cultures. It has been reported that hypercapnia attenuated endotoxin-induced inflammation through inhibiting nuclear factor (NF)- $\mathrm{B}$ activation $(21,30)$. The earlier research results appear to contradict those of the present study. However, the difference may be due to the underlying mechanism, whereby hypercapnia would exert its effects on IL-1 $\beta$ expression in the hypoxic blood. Endotoxin may induce IL-1 $\beta$ expression through the Toll-like receptor/NF- $\kappa \mathrm{B}$ pathway (31-33). Hypoxia may also activate the NLRP3 inflammasome via inducing reactive oxygen species (ROS) overproduction, which can promote the secretion of IL-1 $\beta$ (34-37). In the present study, it was observed that hypercapnia alone may not be sufficient to increase the expression of IL-1 $\beta$, but hypercapnia may exert its effects in the presence of hypoxia. It was suggested that hypercapnia can induce ROS overproduction via intensifying hypoxia, may activate the NLRP3 inflammasome and promote IL-1 $\beta$ release. In the central nervous system, it was previously demonstrated that hypercapnia-induced NLRP3 inflammasome activation in hypoxia-activated microglia upregulated the expression of IL-1 $\beta$ (6). These findings are consistent with the effects of hypercapnia on IL-1 $\beta$ expression in the hypoxic blood in the present study.
To elucidate the mechanism through which hypercapnia can increase BBB permeability in hypoxemic rats through upregulating the expression of IL-1 $\beta$, the expression levels of IL-1R1, p-IRAK-1 and tight junctional proteins (ZO-1, occludin and claudin-5) in cerebral vascular endothelial cells were examined. It was demonstrated that hypercapnia increased the expression of IL-1R 1 and p-IRAK-1 and downregulated the expression of tight junctional proteins in hypoxic cerebral vascular endothelial cells. The expression of tight junctional proteins was markedly increased following treatment with IL-1Ra, an IL-1 receptor antagonist. IRAK-1 is critically involved in the regulation of intracellular signaling networks. IRAK-1 may perform distinct functions, including activation of NF- $\mathrm{BB}(38)$, which is closely associated with the disruption of the BBB $(39,40)$. Taken together, these findings suggest that hypercapnia may aggravate $\mathrm{BBB}$ disruption in hypoxemic rats via inducing IL- $1 \beta$ overproduction. However, a limitation of the present study is that other cytokines (e.g., tumor necrosis factor- $\alpha$ ) were not investigated, which should be addressed in future studies.

In summary, the present study demonstrated that hypercapnia serves as a stimulus triggering inflammation in the hypoxic blood. In this setting, hypercapnia may contribute to IL-1 $\beta$ overproduction in the hypoxic blood, and then downregulate the expression of tight junctional proteins in the hypoxic cerebral vascular endothelial cells, thereby further disrupting BBB integrity in hypoxemic rats. The increased expression of tight junctional proteins in hypoxic cerebrovascular endothelial cells when the effects of IL-1 $\beta$ are blocked by IL-1Ra further supports this hypothesis. Thus, the cascade of hypercapnia-induced IL- $1 \beta$ overproduction in hypoxic blood may be a potential target for ameliorating $\mathrm{BBB}$ disruption.

\section{Acknowledgements}

The authors would like to thank Zhengkang Ding and Zixi Yang for the technical support.

\section{Funding}

This study was supported by the Natural Science Foundation of Guangdong Province (grant nos. 2016A030311043 and 2017A030313691), the Medical Scientific Research Foundation of Guangdong Province (grant nos. A2019135 and A2017284), the Scientific Research Project of Guangdong Provincial Bureau of Traditional Chinese Medicine (grant no. 20201045) and the Science and Technology Program of Guangzhou (grant no. 202002030338).

\section{Availability of data and materials}

The datasets generated and/or analyzed during the present study are available from the corresponding author on reasonable request.

\section{Authors' contributions}

$\mathrm{HZ}$ conceived the project and designed the experiments. HD carried out the assessment of BBB permeability and IL-1 $\beta$ 
evaluation by ELISA. XuL established the rat model of hypercapnia/hypoxemia. XiL carried out human whole-blood cultures and treatment. MW carried out cerebrovascular endothelial cell cultures and treatment. YH, LH and YL performed western blotting and immunofluorescence staining. HD and ML conducted the statistical analysis. HD and XuL wrote the manuscript. All the authors have read and approved the final version of the manuscript.

\section{Ethics approval and consent to participate}

The animal experimental protocols were approved by the Experimental Animal Care and Use Committee at Jinan University (approval no. 20171011001). The protocols involving human samples were approved by the Research Ethics Committee of Guangdong Provincial People's Hospital, Guangdong Academy of Medical Sciences, Guangzhou, China [approval no. GDREC2018424H(R1)] and all the participants provided written informed consent.

\section{Patient consent for publication}

Not applicable.

\section{Competing interests}

All the authors declare that they have no competing interests.

\section{References}

1. Matthay MA, Zemans RL, Zimmerman GA, Arabi YM Beitler JR, Mercat A, Herridge M, Randolph AG and Calfee CS: Acute respiratory distress syndrome. Nat Rev Dis Primers 5: 18, 2019.

2. Papazian L, Aubron C, Brochard L, Chiche JD, Combes A, Dreyfuss D, Forel JM, Guerin C, Jaber S, Mekontso-Dessap A, et al: Formal guidelines: Management of acute respiratory distress syndrome. Ann Intensive Care 9: 69, 2019.

3. Broccard AF, Hotchkiss JR, Vannay C, Markert M, Sauty A, Feihl F and Schaller MD: Protective effects of hypercapnic acidosis on ventilator-induced lung injury. Am J Respir Crit Care Med 164: 802-806, 2001.

4. Laffey JG, Tanaka M, Engelberts D, Luo X, Yuan S, Tanswell AK, Post M, Lindsay T and Kavanagh BP: Therapeutic hypercapnia reduces pulmonary and systemic injury following in vivo lung reperfusion. Am J Respir Crit Care Med 162: 2287-2294, 2000.

5. Peltekova V, Engelberts D, Otulakowski G, Uematsu S, Post M and Kavanagh BP: Hypercapnic acidosis in ventilator-induced lung injury. Intensive Care Med 36: 869-878, 2010.

6. Ding HG, Deng YY, Yang RQ, Wang QS, Jiang WQ, Han YL, Huang LQ, Wen MY, Zhong WH, Li XS, et al: Hypercapnia induces IL-1 $\beta$ overproduction via activation of NLRP3 inflammasome: Implication in cognitive impairment in hypoxemic adult rats. J Neuroinflammation 15: 4, 2018.

7. Bowman GL, Dayon L, Kirkland R, Wojcik J, Peyratout G, Severin IC, Henry H, Oikonomidi A, Migliavacca E, Bacher and Popp J: Blood-brain barrier breakdown, neuroinflammation, and cognitive decline in older adults. Alzheimers Dement 14: 1640-1650, 2018.

8. Nwafor DC, Brichacek AL, Mohammad AS, Griffith J, Lucke-Wold BP, Benkovic SA, Geldenhuys WJ, Lockman PR and Brown CM: Targeting the blood-brain barrier to prevent sepsis-associated cognitive impairment. J Cent Nerv Syst Dis 11: $593300084,2019$.

9. Toyama K, Spin JM, Deng AC, Huang TT, Wei K, Wagenhäuser MU, Yoshino T, Nguyen H, Mulorz J, Kundu S, et al: MicroRNA-mediated therapy modulating blood-brain barrier disruption improves vascular cognitive impairment. Arterioscler Thromb Vasc Biol 38: 1392-1406, 2018.
10. Ni P, Dong H, Wang Y, Zhou Q, Xu M, Qian Y and Sun J: IL-17A contributes to perioperative neurocognitive disorders through blood-brain barrier disruption in aged mice. J Neuroinflammation 15: 332, 2018.

11. Montagne A, Barnes SR, Sweeney MD, Halliday MR, Sagare AP Zhao Z, Toga AW, Jacobs RE, Liu CY, Amezcua L, et al: Blood-brain barrier breakdown in the aging human hippocampus. Neuron 85: 296-302, 2015.

12. Iadecola C: Dangerous leaks: Blood-brain barrier woes in the aging hippocampus. Neuron 85: 231-233, 2015.

13. Nation DA, Sweeney MD, Montagne A, Sagare AP, D'Orazio LM, Pachicano M, Sepehrband F, Nelson AR, Buennagel DP, Harrington MG, et al: Blood-brain barrier breakdown is an early biomarker of human cognitive dysfunction. Nat Med 25: 270-276, 2019.

14. Wang B, Li S, Cao X, Dou X, Li J, Wang L, Wang M and Bi Y: Blood-brain barrier disruption leads to postoperative cognitive dysfunction. Curr Neurovasc Res 14: 359-367, 2017.

15. YeZY,Xing HY, Wang B,Liu Mand Lv PY:DL-3-n-butylphthalide protects the blood-brain barrier against ischemia/hypoxia injury via upregulation of tight junction proteins. Chin Med J (Engl) 132: 1344-1353, 2019.

16. Jiao H, Wang Z, Liu Y, Wang P and Xue Y: Specific role of tight junction proteins claudin-5, occludin, and ZO-1 of the blood-brain barrier in a focal cerebral ischemic insult. J Mol Neurosci 44: 130-139, 2011.

17. Dhanda $\mathrm{S}$ and Sandhir R: Blood-brain barrier permeability is exacerbated in experimental model of hepatic encephalopathy via MMP-9 activation and downregulation of tight junction proteins. Mol Neurobiol 55: 3642-3659, 2018.

18. Zenaro E, Piacentino G and Constantin G: The blood-brain barrier in Alzheimer's disease. Neurobiol Dis 107: 41-56, 2017.

19. Obermeier B, Daneman R and Ransohoff RM: Development, maintenance and disruption of the blood-brain barrier. Nat Med 19: 1584-1596, 2013

20. Wang Y, Jin S, Sonobe Y, Cheng Y, Horiuchi H, Parajuli B, Kawanokuchi J, Mizuno T, Takeuchi $\mathrm{H}$ and Suzumura A: Interleukin-1 $\beta$ induces blood-brain barrier disruption by downregulating Sonic hedgehog in astrocytes. PLoS One 9: e110024, 2014.

21. Kimura D, Totapally BR, Raszynski A, Ramachandran C and Torbati D: The effects of $\mathrm{CO}_{2}$ on cytokine concentrations in endotoxin-stimulated human whole blood. Crit Care Med 36: 2823-2827, 2008

22. Nakagawa S, Deli MA, Nakao S, Honda M, Hayashi K, Nakaoke R, Kataoka Y and Niwa M: Pericytes from brain microvessels strengthen the barrier integrity in primary cultures of rat brain endothelial cells. Cell Mol Neurobiol 27: 687-694, 2007.

23. Takata F, Sumi N, Nishioku T, Harada E, Wakigawa T, Shuto H, Yamauchi A and Kataoka Y: Oncostatin M induces functional and structural impairment of blood-brain barriers comprised of rat brain capillary endothelial cells. Neurosci Lett 441: 163-166, 2008.

24. Morofuji Y, Nakagawa S, So G, Hiu T, Horai S, Hayashi K, Tanaka K, Suyama K, Deli MA, Nagata I and Niwa M: Pitavastatin strengthens the barrier integrity in primary cultures of rat brain endothelial cells. Cell Mol Neurobiol 30: 727-735, 2010.

25. Han Q, Lin Q, Huang P, Chen M, Hu X, Fu H, He S, Shen F, Zeng H and Deng Y: Microglia-derived IL-1 $\beta$ contributes to axon development disorders and synaptic deficit through p38-MAPK signal pathway in septic neonatal rats. J Neuroinflammation 14: 52, 2017.

26. Takeuchi M, Taki J, Hayashi K, Higashi M, Tachibana K, Takauchi Y and Imanaka H: Early application of the lung protective ventilation strategy at different stages in two ARDS patients. Masui 53: 514-521, 2004 (In Japanese).

27. Thorens JB, Jolliet P, Ritz M and Chevrolet JC: Effects of rapid permissive hypercapnia on hemodynamics, gas exchange, and oxygen transport and consumption during mechanical ventilation for the acute respiratory distress syndrome. Intensive Care Med 22: 182-191, 1996.

28. Hickling KG, Walsh J, Henderson S and Jackson R: Low mortality rate in adult respiratory distress syndrome using low-volume, pressure-limited ventilation with permissive hypercapnia: A prospective study. Crit Care Med 22: 1568-1578, 1994.

29. Dushianthan A, Cusack R, Chee N, Dunn JO and Grocott MP: Perceptions of diagnosis and management of patients with acute respiratory distress syndrome: A survey of United Kingdom intensive care physicians. BMC Anesthesiol 14: 87, 2014. 
30. Takeshita K, Suzuki Y, Nishio K, Takeuchi O, Toda K, Kudo H, Miyao N, Ishii M, Sato N, Naoki K, et al: Hypercapnic acidosis attenuates endotoxin-induced nuclear factor-[kappa]B activation. Am J Respir Cell Mol Biol 29: 124-132, 2003.

31. Gay NJ, Symmons MF, Gangloff M and Bryant CE: Assembly and localization of Toll-like receptor signalling complexes. Nat Rev Immunol 14: 546-558, 2014.

32. Chen Y, Liu T, Langford P, Hua K, Zhou S, Zhai Y, Xiao H, Luo R, Bi D, Jin $\mathrm{H}$ and Zhou R: Haemophilus parasuis induces activation of NF- $\kappa B$ and MAP kinase signaling pathways mediated by toll-like receptors. Mol Immunol 65: 360-366, 2015.

33. Zhang Y, Lu Y, Ma L, Cao X, Xiao J, Chen J, Jiao S, Gao Y, Liu C, Duan Z, et al: Activation of vascular endothelial growth factor receptor-3 in macrophages restrains TLR4-NF- $\kappa \mathrm{B}$ signaling and protects against endotoxin shock. Immunity 40: 501-514, 2014.

34. Tschopp J and Schroder K: NLRP3 inflammasome activation: The convergence of multiple signalling pathways on ROS production? Nat Rev Immunol 10: 210-215, 2010.

35. Dai Y, Zhang J, Xiang J, Li Y, Wu D and Xu J: Calcitriol inhibits ROS-NLRP3-IL-1beta signaling axis via activation of Nrf2-antioxidant signaling in hyperosmotic stress stimulated human corneal epithelial cells. Redox Biol 21: 101093, 2019.

36. Hoyt LR, Randall MJ, Ather JL, DePuccio DP, Landry CC, Qian X, Janssen-Heininger YM, van der Vliet A, Dixon AE, Amiel E and Poynter ME: Mitochondrial ROS induced by chronic ethanol exposure promote hyper-activation of the NLRP3 inflammasome. Redox Biol 12: 883-896, 2017.
37. Abais JM, Xia M, Zhang Y, Boini KM and Li PL: Redox regulation of NLRP3 inflammasomes: ROS as trigger or effector? Antioxid Redox Signal 22: 1111-1129, 2015.

38. Song YJ, Jen KY, Soni V, Kieff E and Cahir-McFarland E: IL-1 receptor-associated kinase 1 is critical for latent membrane protein 1-induced p65/RelA serine 536 phosphorylation and NF-kappaB activation. Proc Natl Acad Sci USA 103: 2689-2694, 2006.

39. Dong L, Qiao H, Zhang X, Zhang X, Wang C, Wang L, Cui L, Zhao J, Xing Y and Li Y, et al: Parthenolide is neuroprotective in rat experimental stroke model: Downregulating NF- $\kappa$ B, phospho-p38MAPK, and caspase-1 and ameliorating BBB permeability. Mediators Inflamm 2013: 370804, 2013.

40. Zhao T, Zhang X, Zhao Y, Zhang L, Bai X, Zhang J, Zhao X, Chen L, Wang L and Cui L: Pretreatment by evodiamine is neuroprotective in cerebral ischemia: Up-regulated pAkt, pGSK3 $\beta$, down-regulated NF- $\kappa \mathrm{B}$ expression, and ameliorated BBB permeability. Neurochem Res 39: 1612-20, 2014.

This work is licensed under a Creative Commons Attribution-NonCommercial-NoDerivatives 4.0 International (CC BY-NC-ND 4.0) License. 